\title{
Clinical Trials in Hepatocellular Carcinoma: An Update
}

\author{
Ying-Chun Shen ${ }^{a, b}$ Zhong-Zhe Lin ${ }^{a, b, c}$ Chih-Hung Hsu ${ }^{a, b, c, d}$ \\ Chiun Hsua,b,c,d Yu-Yun Shao ${ }^{b, d}$ Ann-Lii Cheng ${ }^{b, c, d}$ \\ a National Center of Excellence for Clinical Trial and Research, b Department of Oncology, \\ c Department of Internal Medicine, National Taiwan University Hospital, and \\ d Graduate Institute of Oncology, School of Medicine, National Taiwan University, Taiwan (ROC)
}

\section{Key Words}

Clinical trial $\cdot$ Hepatocellular carcinoma $\cdot$ Molecular targeted therapy

\begin{abstract}
The success of sorafenib has spurred an explosive increase of clinical trials testing novel molecular targets and other agents in the treatment of hepatocellular carcinoma (HCC). The paradigm of the studies has been characterized by three noticeable changes. First, the molecular targets of interest have expanded from angiogenesis to cancer cell-directed oncogenic signaling pathways for advanced HCC treatment. Agents targeting EGFR, FGFR, PI3K/Akt/mTOR, TGF- $\beta$, c-Met, MEK, IGF signaling, and histone deacetylase have been actively explored. Second, the target indication has shifted from advanced stage to early or intermediate stages of disease. The feasibility of combining locoregional therapies and targeted agents, and the use of novel agents after curative treatments are currently under active investigation. Finally, the therapeutic strategy has shifted from monotherapy to combination targeted therapy. We aim to provide a comprehensive overview of newly disclosed and ongoing clinical trials for the treatment of HCC.

Copyright @ 2013 S. Karger AG, Basel
\end{abstract}

Ying-Chun Shen and Zhong-Zhe Lin contributed equally to this work. 
Sorafenib, a multi-target anti-angiogenic agent, was the first systemic therapy approved for the treatment of advanced hepatocellular carcinoma (HCC) [1,2]. The success of sorafenib has spurred an explosive increase of clinical trials testing many novel molecular targeted agents in HCC. In recent years, the paradigm of the studies has been characterized by some noticeable changes. First, the molecular targets of interest have expanded from angiogenesis to cancer cell-directed oncogenic signaling pathways. Second, the target indication has shifted from advanced HCC toward early or intermediate HCC. Third, the therapeutic strategy has moved from monotherapy to combination therapy. In this article, we will provide a comprehensive, up-to-date review of clinical trials in HCC.

We searched for all interventional studies in HCC in ClinicalTrials.gov. Studies that met the following criteria were selected: (1) molecular targeted therapy as palliative treatment for advanced or intermediate HCC (in combination with locoregional therapies) or adjuvant treatment for early HCC following curative treatment; (2) studies which were open for recruitment (recruiting or not yet recruiting) as of February 2013 or studies which were closed (active but not recruiting, completed, suspended or terminated) after 2011. We also searched PubMed and meeting abstracts of the American Society of Clinical Oncology (ASCO), the American Association for the Study of Liver Diseases (AASLD), the International Liver Congress, the International Liver Cancer Association (ILCA), and the Asian Pacific Association for the Study of Liver (APASL) from January 2011 to February 2013 for full or interim reports of those included trials. The following data from published studies are shown in the tables: number of evaluable patients, objective response rate (ORR), disease control rate (DCR), time-to-progression (TTP), progression-free survival (PFS) and overall survival (OS).

\section{Clinical Trials of Molecular Targeted Therapy for Advanced HCC}

Data from clinical trials on a variety of molecular targeted therapies for advanced HCC are shown in table 1 [3-56].

\section{Anti-angiogenic Agents}

Angiogenesis is so far the most extensively studied therapeutic target of HCC. The efficacy of novel anti-angiogenic tyrosine kinase inhibitors (TKI) for sorafenib-naive advanced HCC has been investigated in several phase III, randomized, controlled trials. However, to date, none of these novel anti-angiogenic TKIs has exhibited superior efficacy to sorafenib. Sunitinib [3] and linifanib (ABT-869) [9], both primarily targeting vascular endothelial growth factor receptor (VEGFR) and platelet-derived growth factor receptor (PDGFR), failed to prolong OS compared to sorafenib (8.1 months for sunitinib vs. 10.0 months for sorafenib, $\mathrm{P}=0.0019$; 9.1 months for linifanib vs. 9.8 months for sorafenib, $\mathrm{P}>0.05)$, and were associated with relatively more grade 3 or 4 adverse events than sorafenib was. Brivanib, which targets VEGFR, PDGFR and fibroblast growth factor receptor (FGFR), also failed to prolong OS (9.5 months for brivanib vs. 9.9 months for sorafenib, $\mathrm{P}>0.05$ ) but had a more favorable toxicity profile than sorafenib [5]. Lenvatinib (E7080), a TKI of VEGFR, PDGFR, FGFR, RET and c-Kit, resulted in a high ORR of 33\% per modified response evaluation criteria in solid tumors (mRECIST) in a phase I/II trial [12], and is currently undergoing phase III investigation.

The efficacy of brivanib after sorafenib failure has also been investigated in a phase III, randomized, placebo-controlled study (BRISK-PS study) [6]. Brivanib, compared to placebo, resulted in a higher ORR (11.5\% vs. $1.9 \%$; per mRECIST) and a longer median TTP (4.3 months vs. 2.7 months, $\mathrm{P}=0.0001)$, but did not significantly increase the OS (9.4 months 


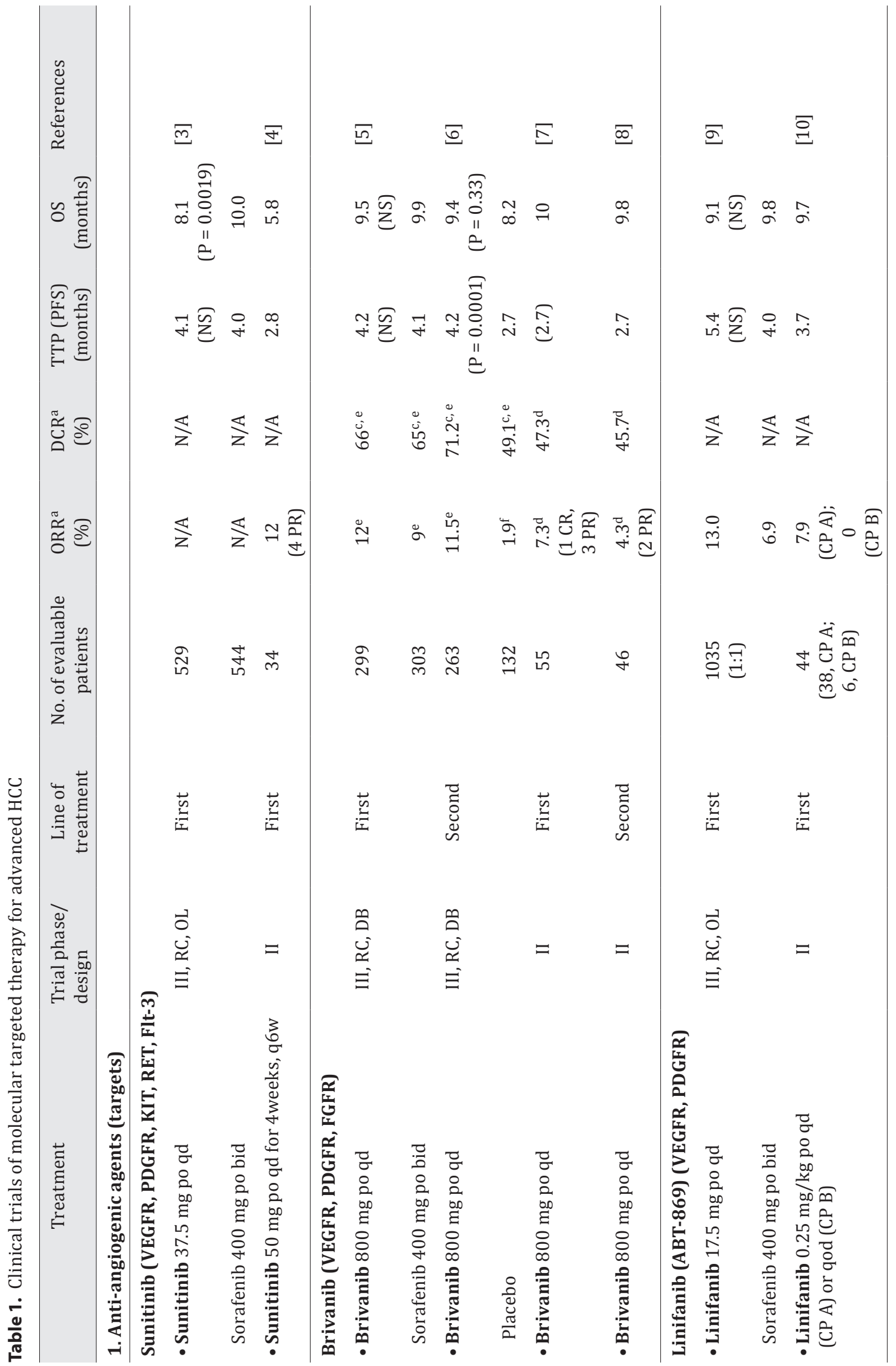


Cancer
Liver Cancer 2013;2:345-364

DOI: $10.1159 / 000343850$
Published online: August 26, 2013

Shen et al.: Clinical Trial Updates for HCC

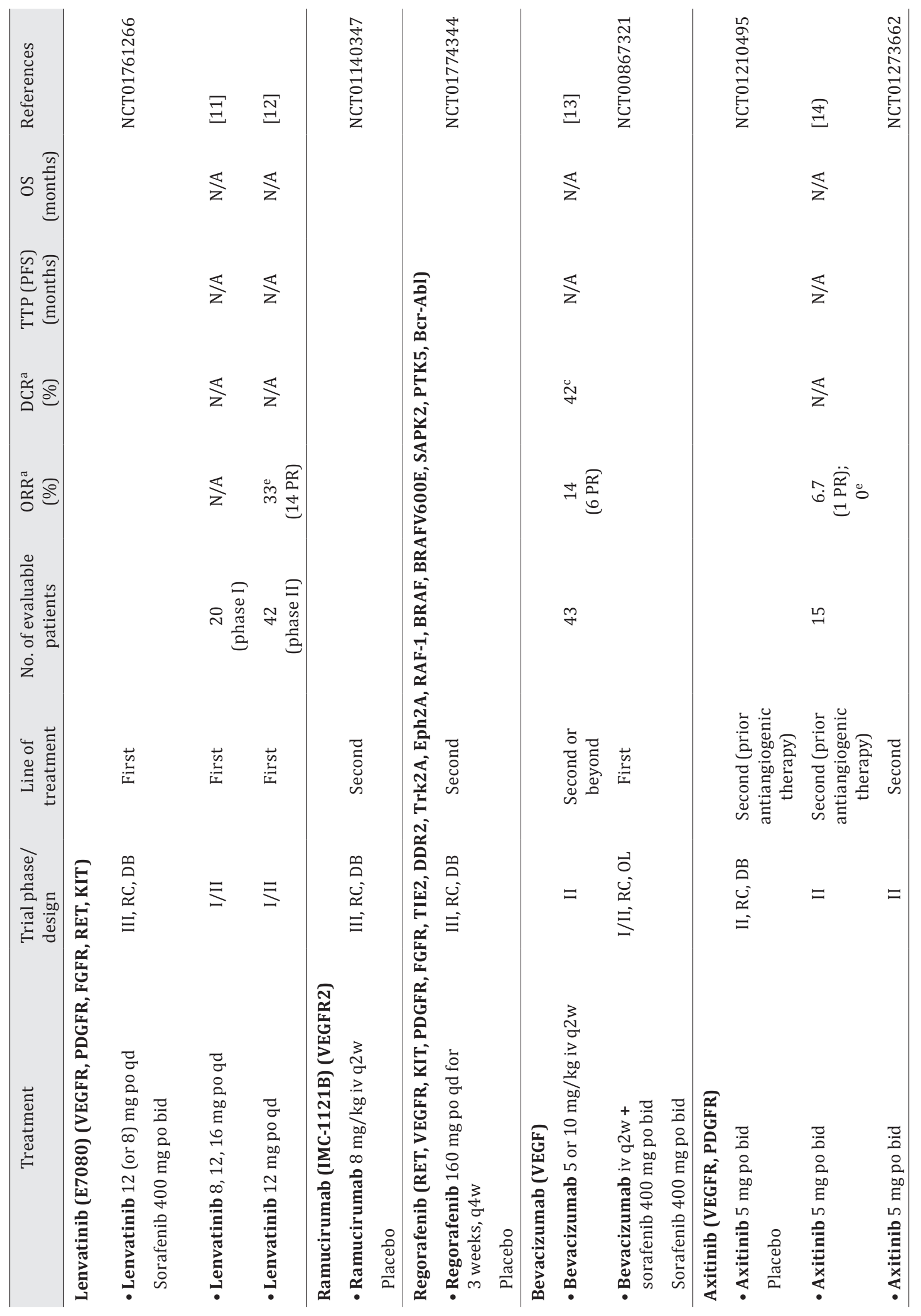

KARGER 
Cancer

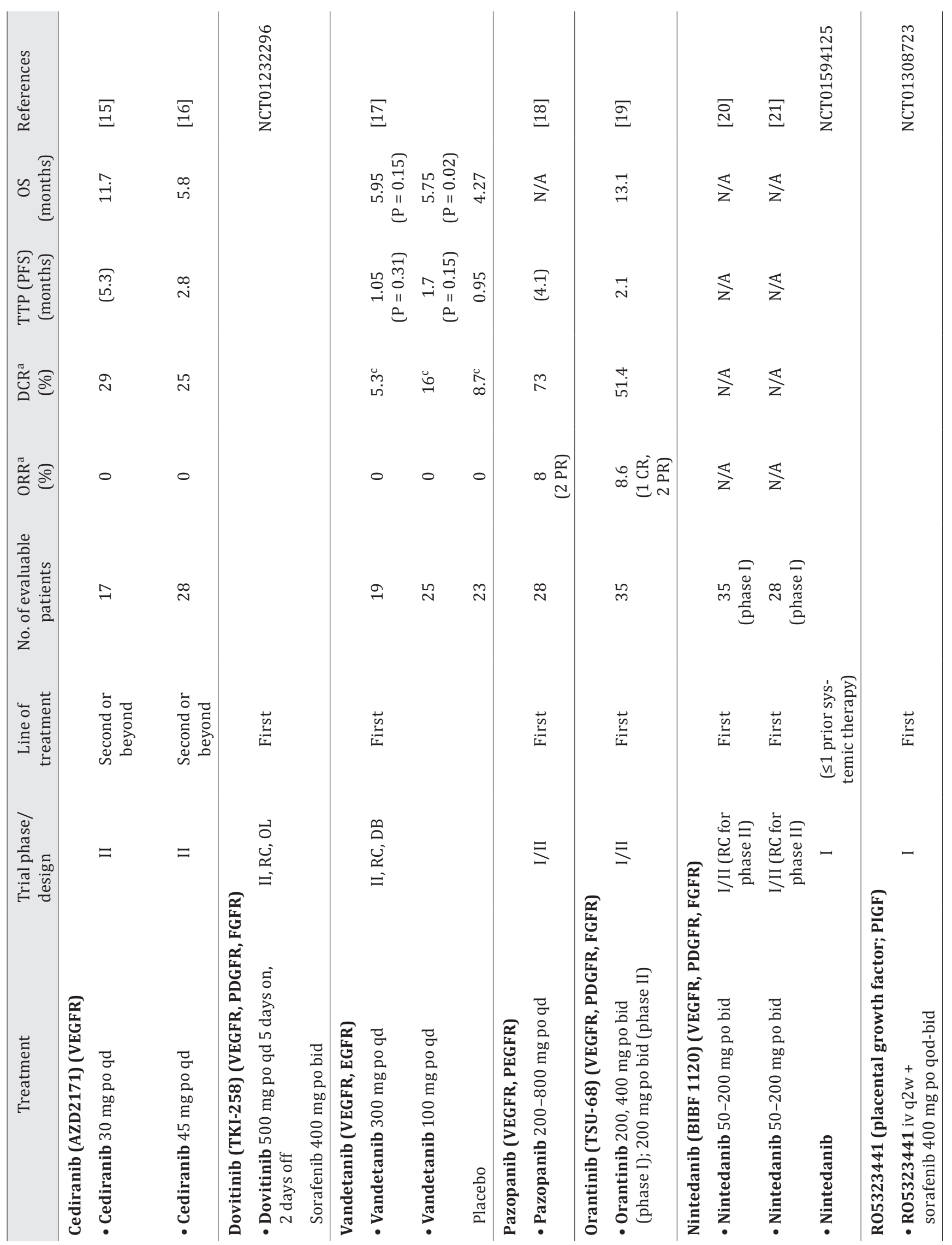




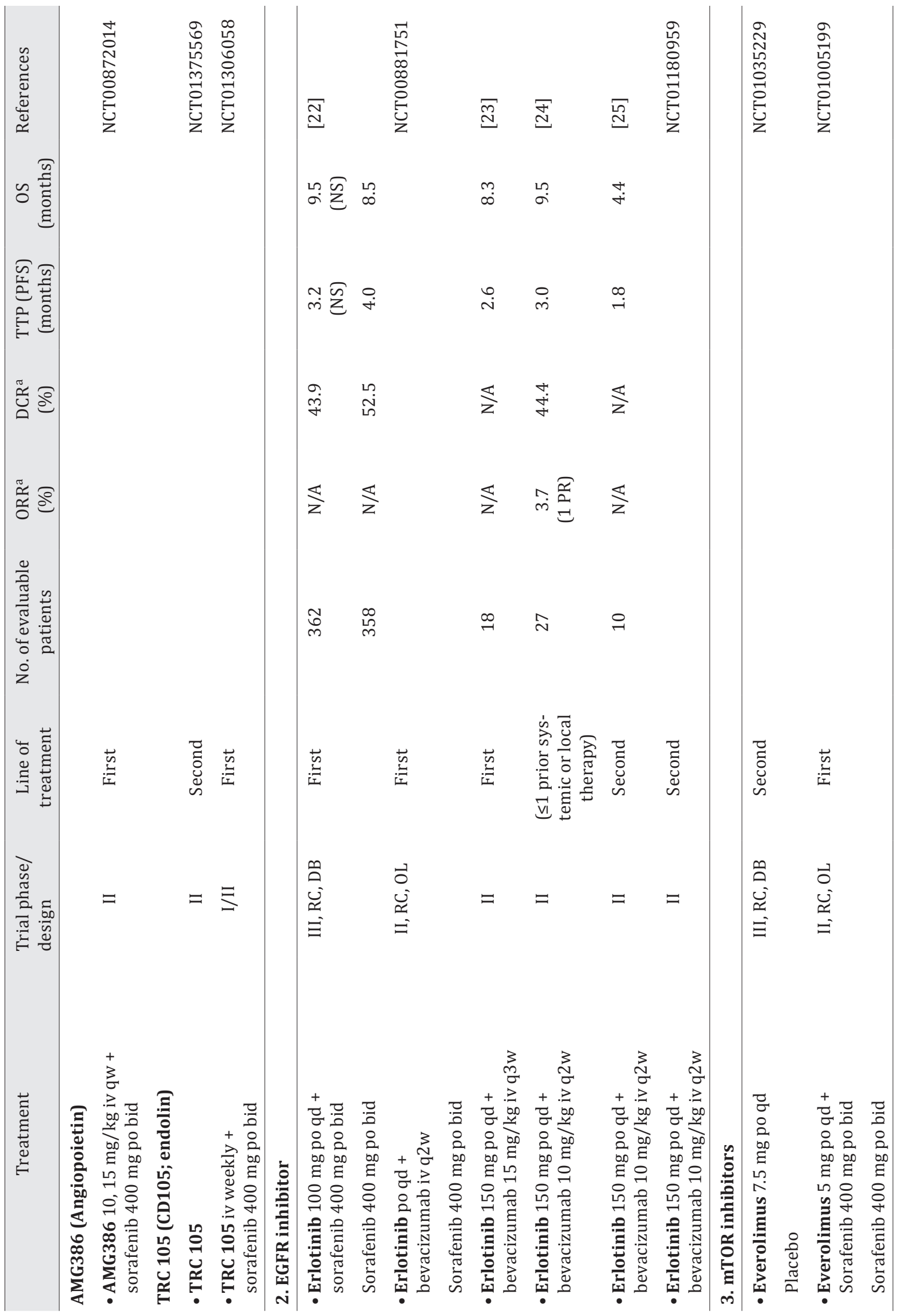




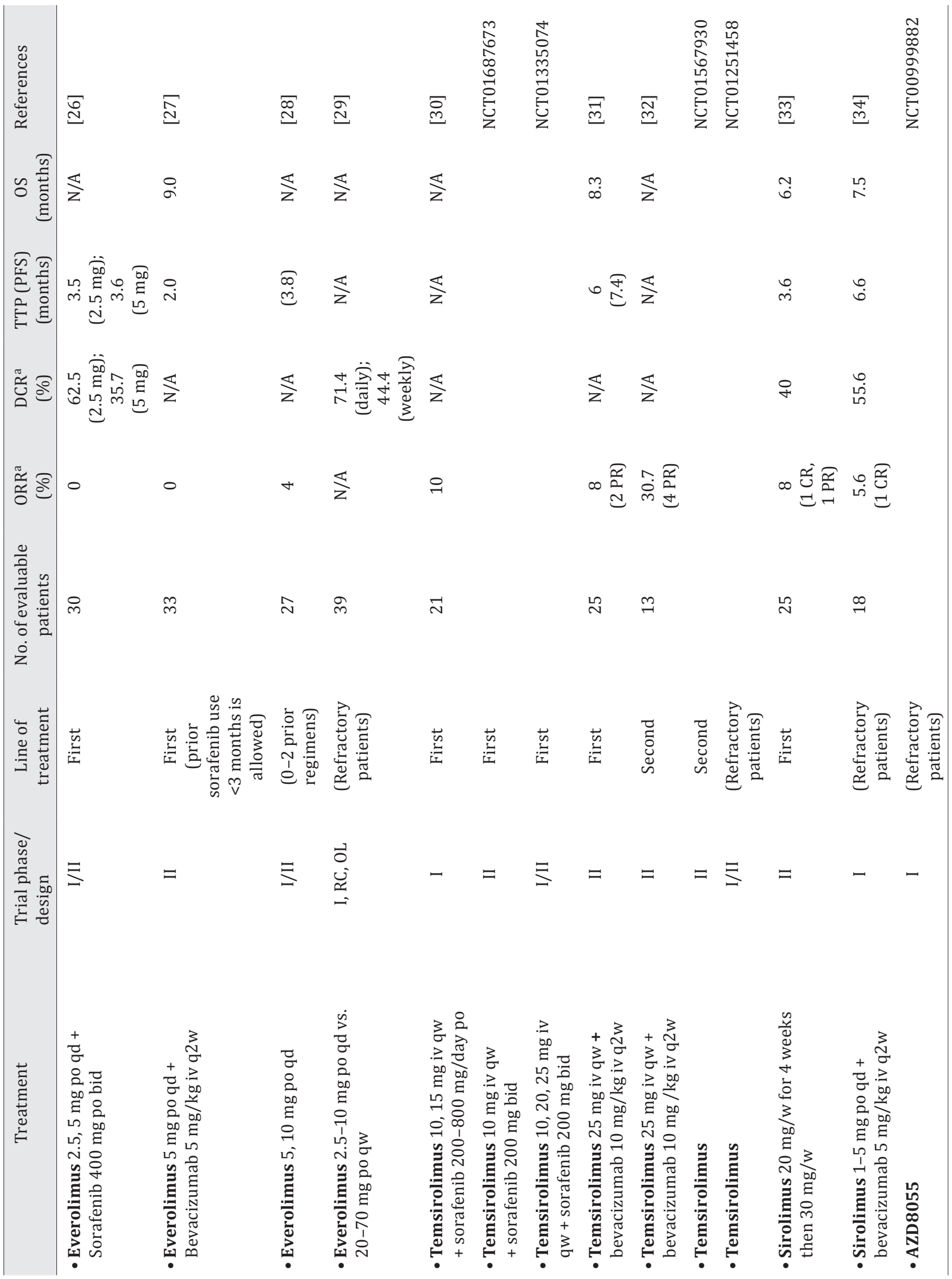




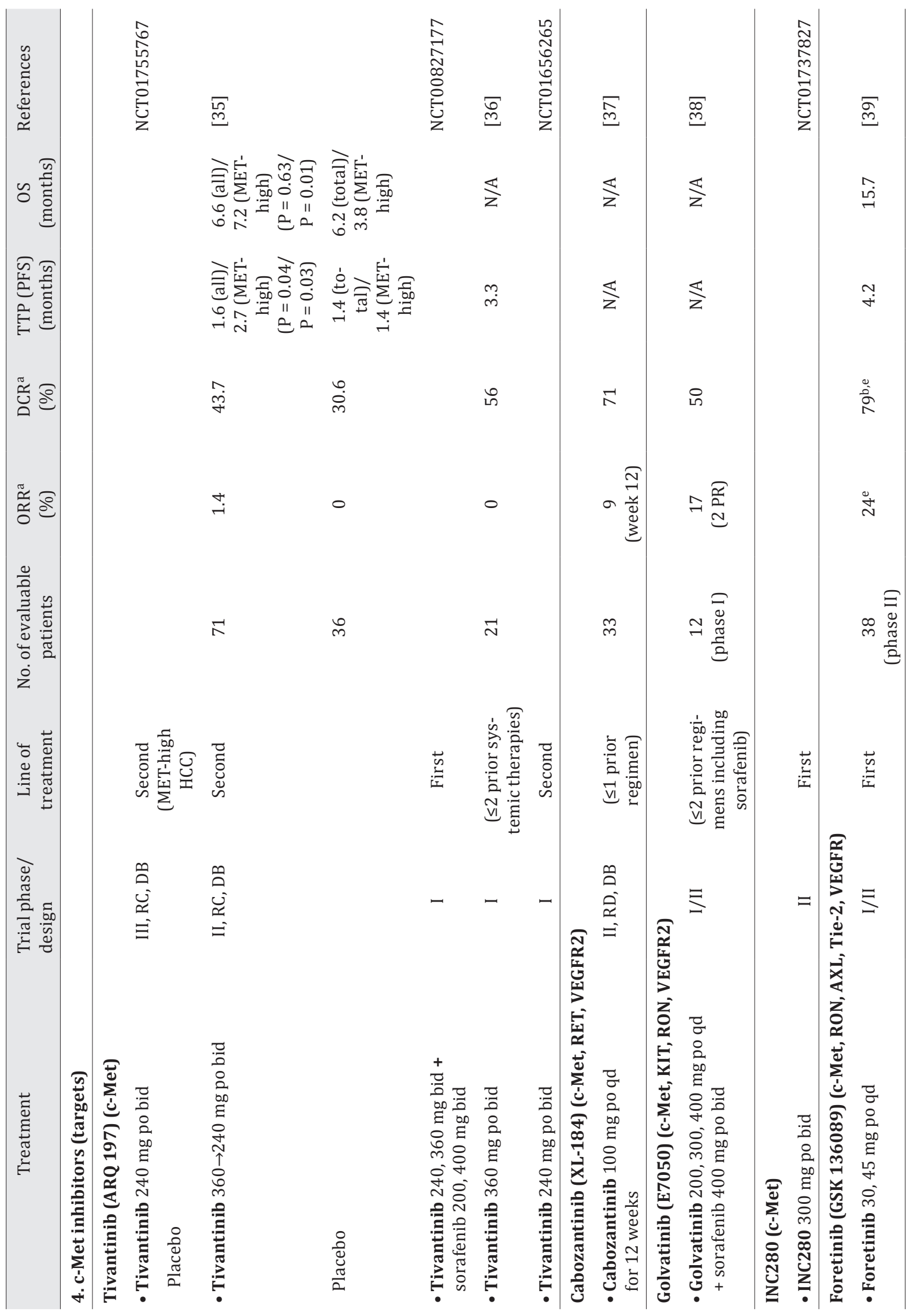




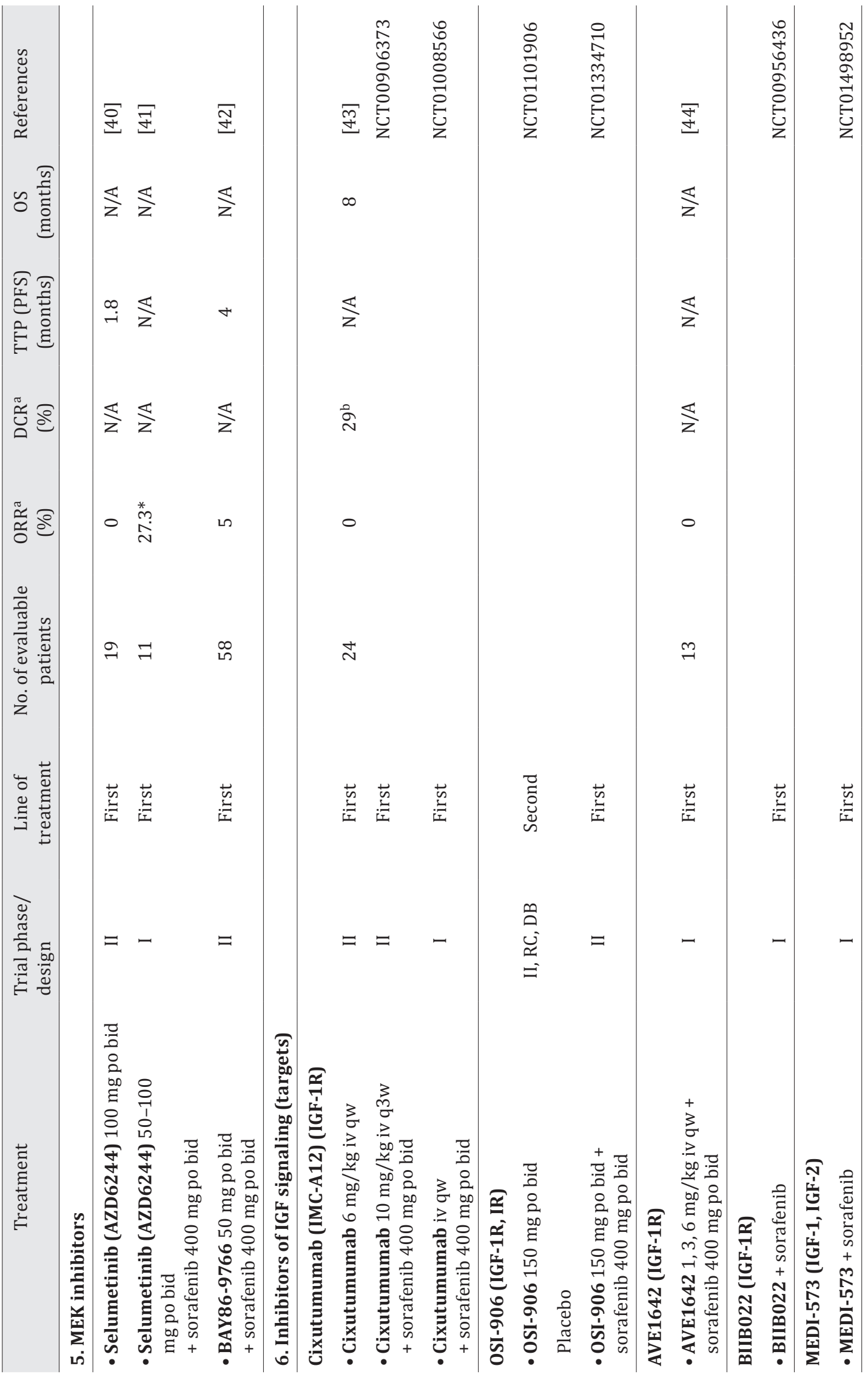

KARGER 


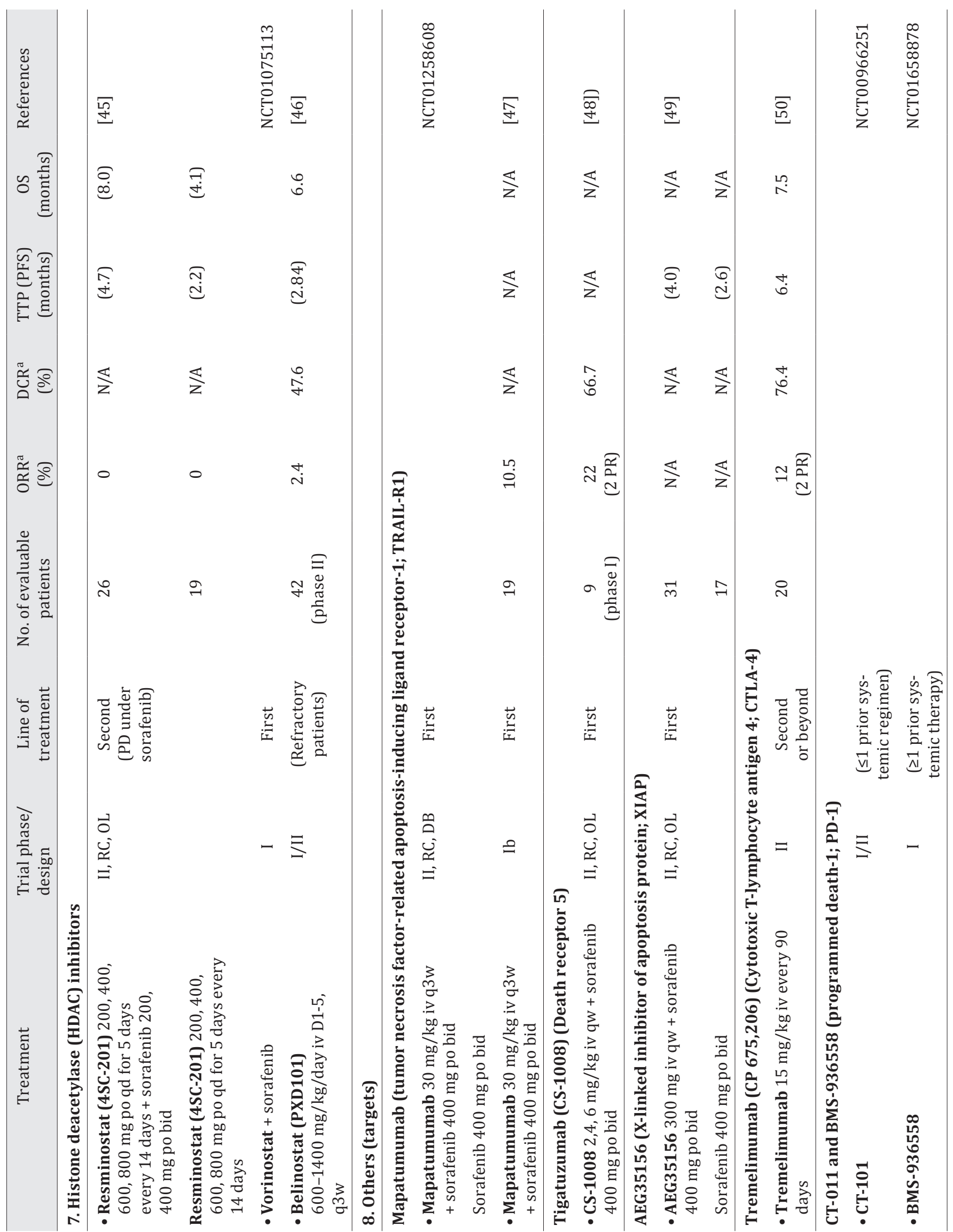




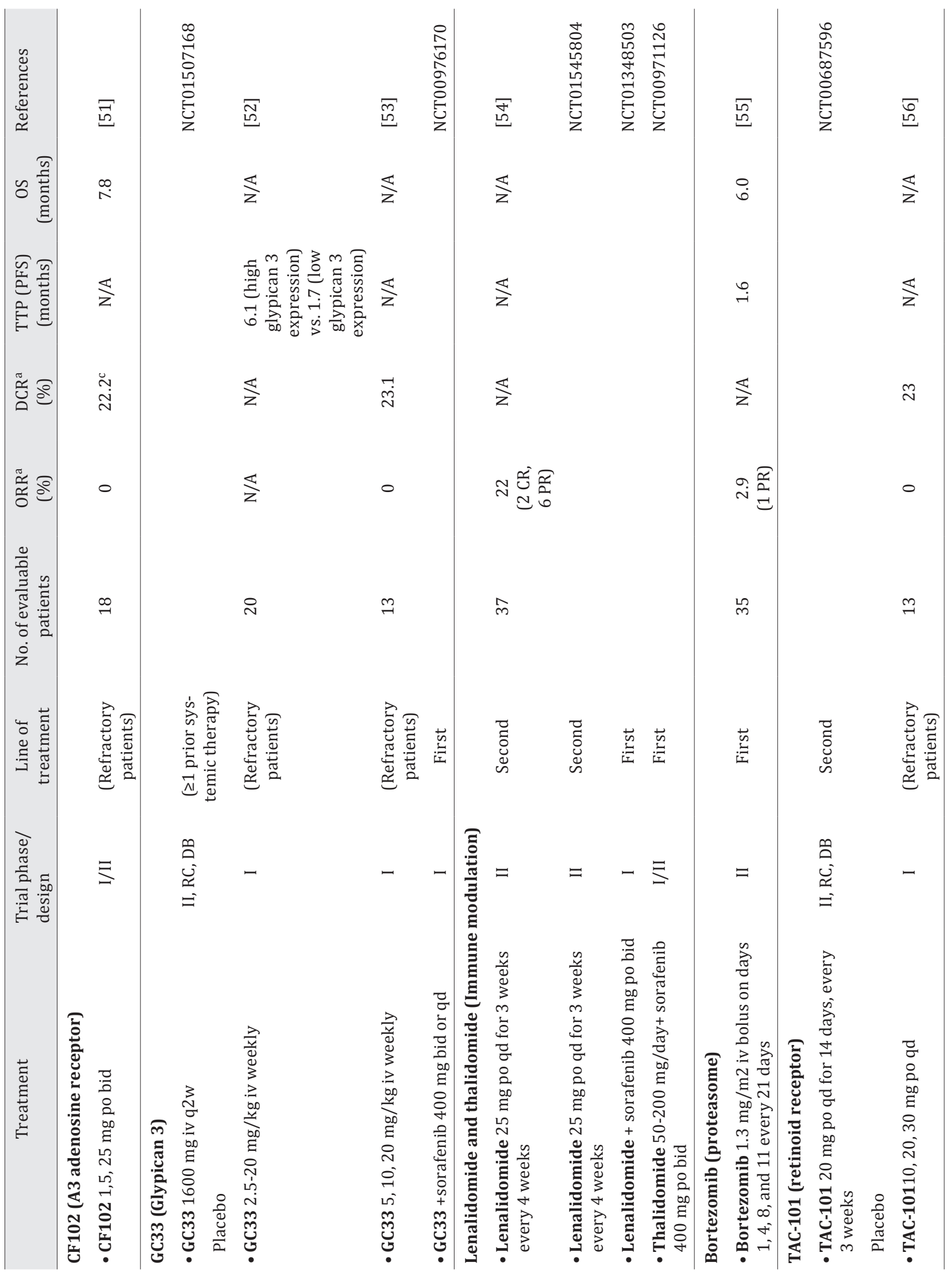




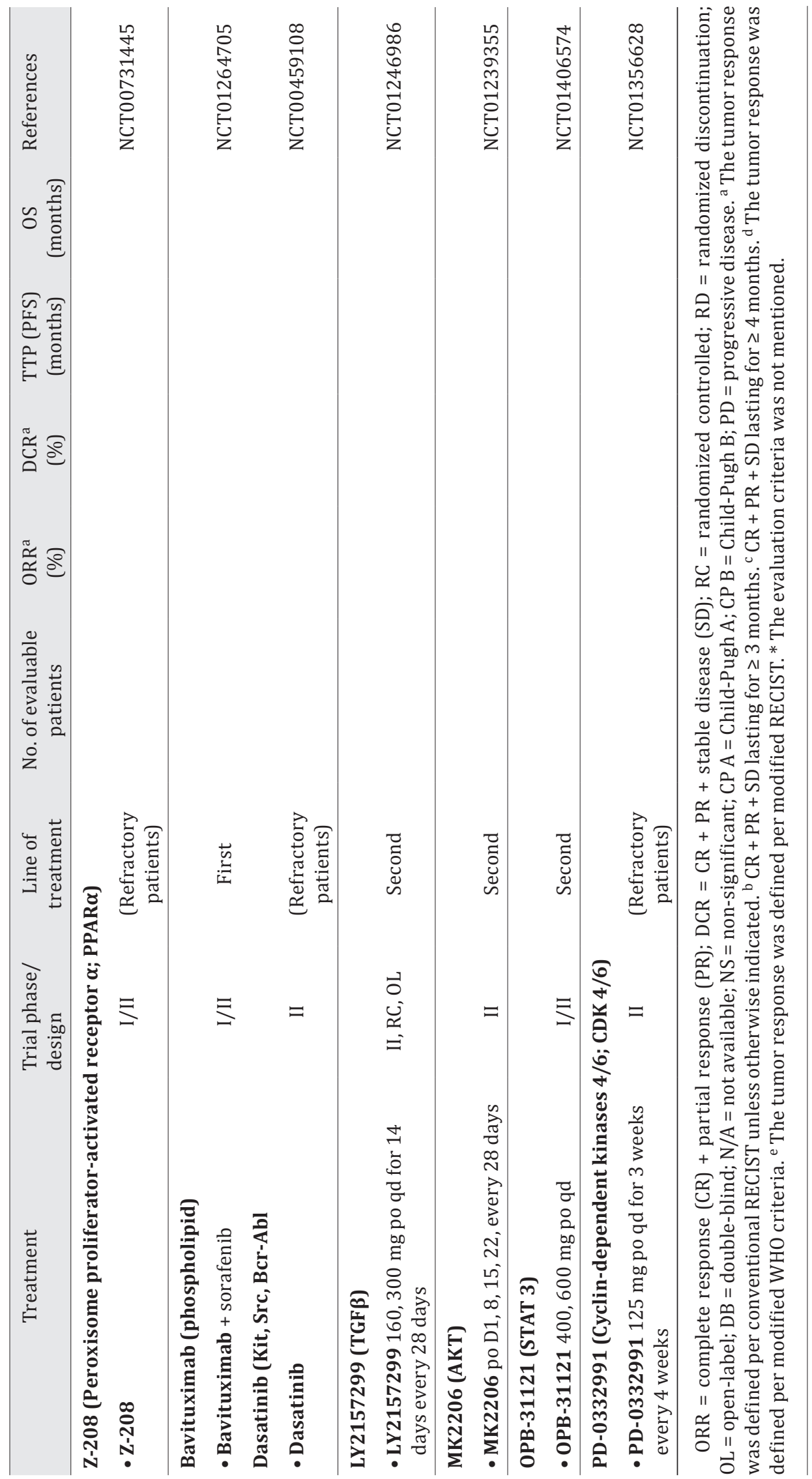


vs. 8.2 months, $\mathrm{P}=0.33$ ). The efficacy of other second-line anti-angiogenic agents (ramucirumab, regorafenib and axitinib) remains undetermined.

\section{EGFR Inhibitor}

The combination of anti-angiogenic therapy and erlotinib has been investigated. In a phase III, randomized, controlled, double-blind trial (SEARCH trial) [22], sorafenib plus erlotinib, compared to sorafenib plus placebo, did not prolong either TTP (3.2months vs. 4.0 months, $\mathrm{P}>0.05$ ) or OS ( 9.5 months vs. 8.5 months; $\mathrm{P}>0.05$ ). In several completed phase II single-arm studies, bevacizumab (anti-VEGF monoclonal antibody) plus erlotinib resulted in a modest anti-tumor activity compared to the historical control of sorafenib or bevacizumab [23-25].

\section{mTOR Inhibitors}

Everolimus (RAD001) is the most extensively studied mTOR inhibitor for the treatment of HCC. The recommended phase II dose of everolimus was 7.5 or $10 \mathrm{mg}$ per day for monotherapy in HCC patients [28, 29]. A phase III, randomized, placebo-controlled trial testing the efficacy of everolimus $7.5 \mathrm{mg}$ po qd after sorafenib failure has completed patient recruitment, and the results will be available by the end of 2013. The maximum tolerated dose of everolimus was determined to be $2.5 \mathrm{mg}$ per day for combination with sorafenib [26]. However, everolimus at this dose level was considered biologically inactive and unlikely to improve the efficacy of sorafenib through mTOR inhibition.

A phase II trial testing the efficacy of temsirolimus $25 \mathrm{mg}$ iv weekly plus bevacizumab $10 \mathrm{mg} / \mathrm{kg}$ iv biweekly for first-line treatment was prematurely stopped due to futility [31]. However, the same combination regimen resulted in a higher ORR (per conventional RECIST) of $30.7 \%$ and fair tolerability in the first 13 patients in a phase II trial for patients in whom sorafenib failed [32].

\section{c-Met Inhibitors}

c-Met signaling is considered essential for hepatocarcinogenesis [57]. Foretinib (GSK 136089), the first multi-target c-MET TKI to undergo clinical investigation, produced a promising ORR (per mRECIST) of 24\%, median TTP of 4.2 months, and median OS of 15.7 months in 38 sorafenib-naïve HCC patients [39]. Other c-Met inhibitors have been primarily evaluated in HCC patients in whom sorafenib had failed. Tivantinib (ARQ 197), a selective non-ATP competitive inhibitor of c-MET, has been tested in a phase II, randomized, placebocontrolled trial [35]. Tivantinib, compared to placebo, improved median TTP from 1.4 to 1.6 months in molecularly unselected HCC patients with a hazard ratio (HR) of $0.64(\mathrm{P}=0.04)$. Importantly, tivantinib almost doubled median TTP (2.7 months vs. 1.4 months, $\mathrm{HR}=0.43$, $\mathrm{P}=0.03)$ and median OS (7.2 months vs. 3.8 months, $\mathrm{HR}=0.38, \mathrm{P}=0.01)$ in patients with high c-Met-expressing tumors ( $\geq 2+$ staining intensity in $\geq 50 \%$ of tumor cells by an immunohistochemical method). A confirmatory phase III, randomized, placebo-controlled trial was subsequently launched to evaluate the efficacy of tivantinib in HCC patients who had high cMet expression in their tumors and developed progressive disease under sorafenib therapy. c-Met inhibitors are generally well tolerated except for increased incidence of grade 3 or 4 neutropenia, anemia and thrombocytopenia (14.1, 11.3 and 5.6\%, respectively).

\section{MEK Inhibitors}

Selumetinib (AZD6244) $100 \mathrm{mg}$ po bid resulted in a short TTP of 1.8 months in the first 19 treatment-naïve HCC patients of a phase II trial, although it did induce down-regulation of ERK phosphorylation in post-treatment tumor tissue [40]. Selumetinib [41] and BAY86-9766 [42] were investigated in early-phase trials for their combination activity with 
sorafenib. The combination of sorafenib and selumetinib resulted in an ORR of $27.3 \%$ in the first 11 patients, but this finding needs to be validated.

\section{Inhibitors of IGF Signaling}

Several IGF- or IGF-1R-targeted agents, either as single agents or in combination with sorafenib, have undergone early-phase investigations $[43,44]$. However, several toxicities, such as hyperglycemia, hyperbilirubinemia and elevation of liver enzymes, following combination therapy have limited the development of OSI-906, AVE1642 and BIIB022.

\section{Other Molecular Targeted Agents}

Many other signaling pathways are also involved in hepatocarcinogenesis, including histone deacetylase (HDAC), tumor necrosis factor-related apoptosis-inducing ligand receptor-1 (TRAIL-R1), death receptor 5 (DR5), X-linked inhibitor of apoptosis protein (XIAP), proteasome, retinoid receptor, peroxisome proliferator-activated receptor $\alpha$ (PPAR $\alpha$ ), phospholipid, transformation growth factor- $\beta$ (TGF- $\beta$ ), AKT, STAT3 and cyclin-dependent kinases. In addition, some molecular targets expressed either on immune cells (such as cytotoxic T-lymphocyte antigen and programmed death-1) or cancer cells (such as A3 adenosine receptor and glypican 3) provide opportunities for immunotherapy. Corresponding targeted agents are being actively studied in phase I/II or II trials for their feasibility. Noticeably, lenalidomide (an immune moderator) resulted in a higher ORR of $22 \%$ per conventional RECIST (two complete responders and six partial responders) in 37 American patients in whom sorafenib had failed [54]. Another study testing the efficacy of lenalidomide as second-line treatment is ongoing in Asian HCC patients.

\section{Clinical Trials of Molecular Targeted Therapy in Combination with Locoregional Therapy}

Data from clinical trials on a variety of molecular targeted therapies in combination with locoregional therapy are shown in table 2 [58-68].

\section{Sorafenib}

The feasibility of combining locoregional therapy and sorafenib for HCC treatment has been evaluated in many clinical trials. In a phase III, randomized, placebo-controlled trial, patients whose hepatic tumors had $\geq 25 \%$ tumor necrosis/shrinkage after one or two sessions of transarterial chemoembolization (TACE) were randomized to sorafenib or placebo. However, the addition of sorafenib failed to prolong TTP (5.4 months vs. 3.7 months; $\mathrm{HR}=0.87 ; \mathrm{P}=0.252$ ) [58]. Subsequently, a number of phase II trials evaluating the efficacy and safety of conventional TACE or TACE with doxorubicin-eluting beads (DEB) with concurrent sorafenib (which started within 14 days before or after TACE was carried out) revealed inconsistent results [59-64]. The diversity of study designs created confounding factors including primary endpoints, patient populations, TACE procedures, timing of randomization, and drug administration may account for these conflicting results [69]. Another two phase III, randomized, placebo-controlled trials evaluating the efficacy of sorafenib in combination with conventional TACE or DEB-TACE are ongoing.

In the phase II SORAMIC trial (local ablation group), patients with early HCC receive a maximum of two curative radiofrequency ablation (RFA) sessions. Randomization to sorafenib or placebo was performed after completion of RFA. Several phase I or II trials eval- 


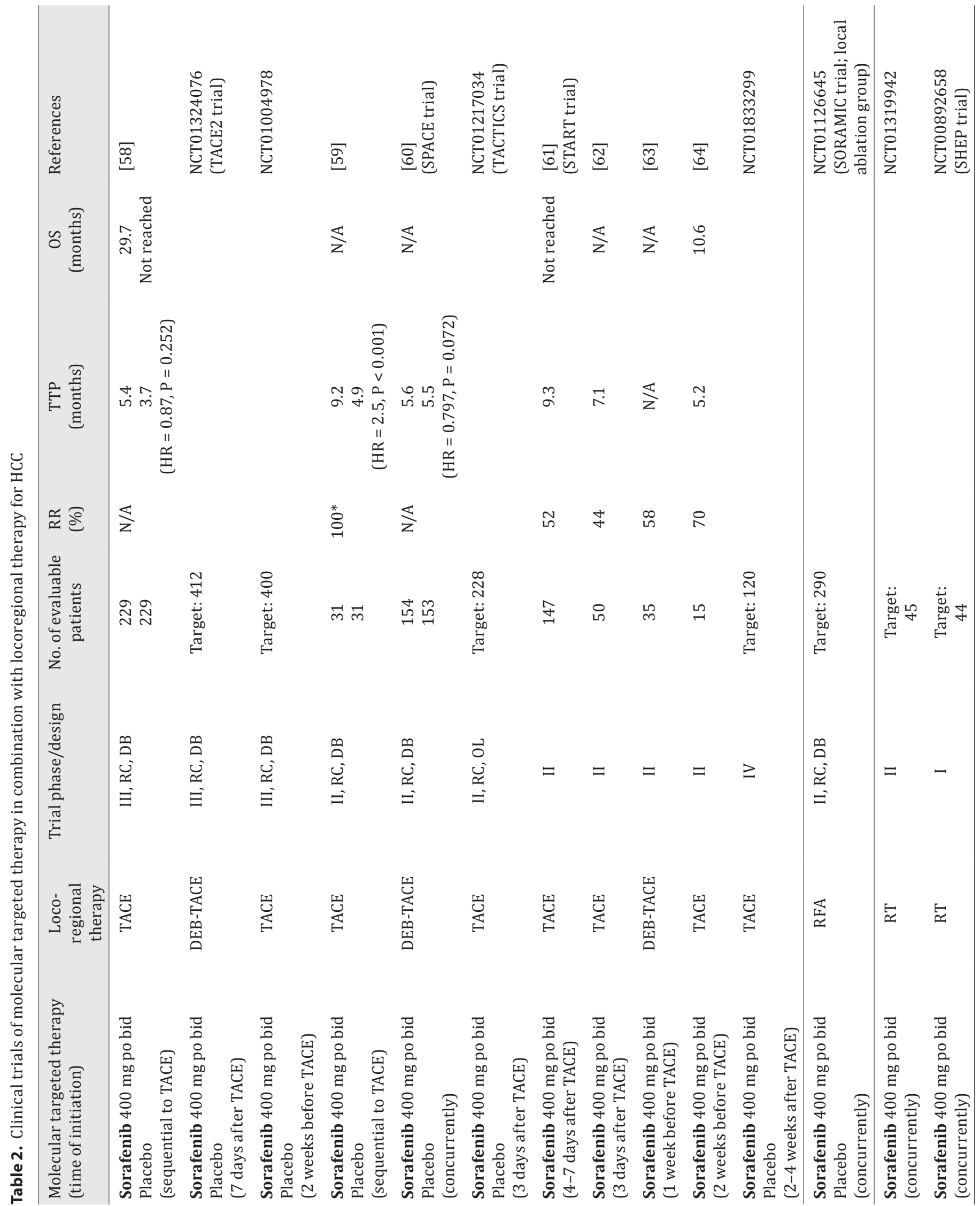




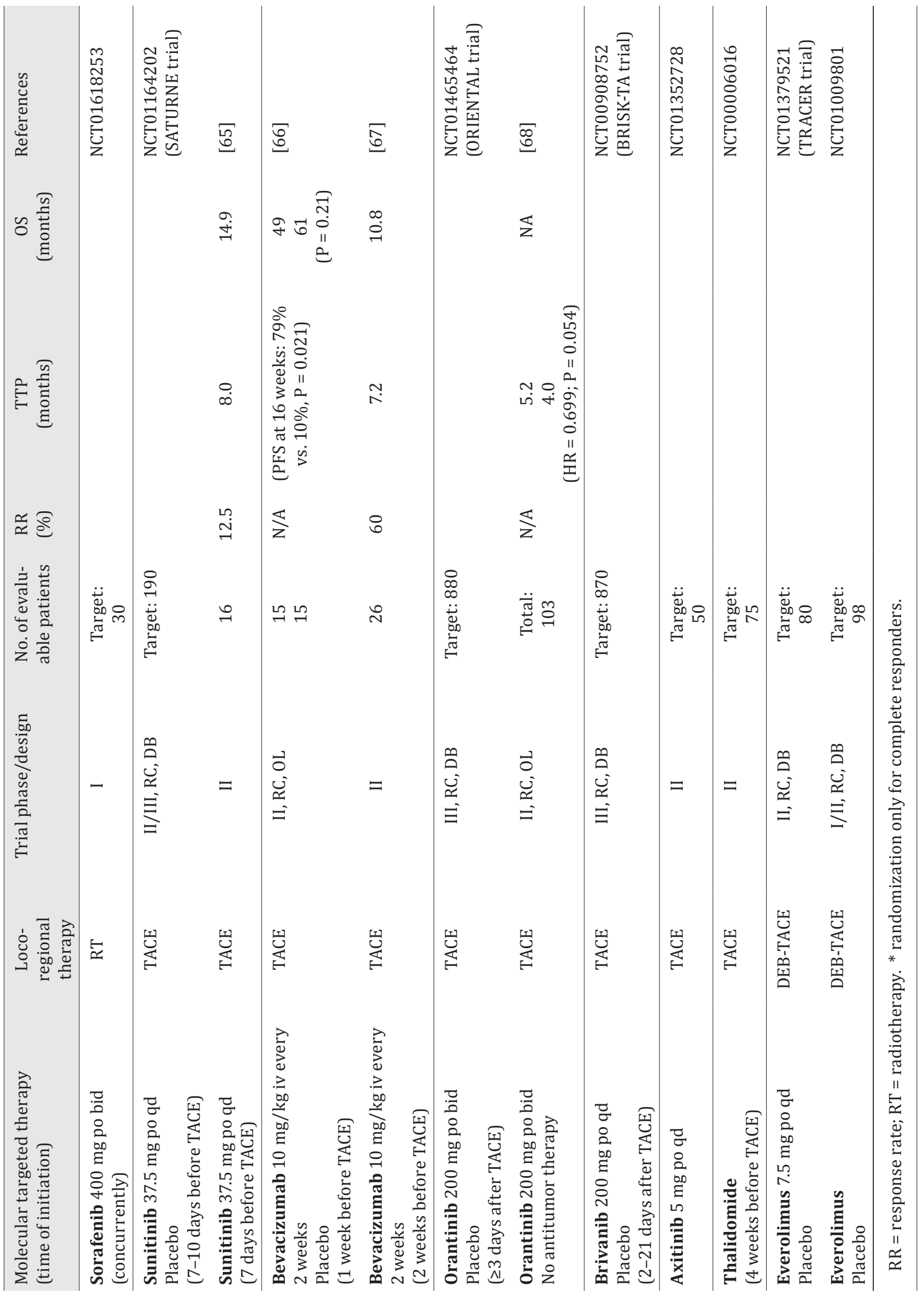


Shen et al.: Clinical Trial Updates for HCC

Table 3. Clinical trials of adjuvant molecular targeted therapy following curative treatment for HCC

\begin{tabular}{|c|c|c|c|c|c|}
\hline Treatment & Curative treatment & Trial phase/design & $\begin{array}{c}\text { No. of evaluable } \\
\text { patients }\end{array}$ & $\begin{array}{c}\text { Recurrence-free } \\
\text { survival } \\
\text { (months) }\end{array}$ & References \\
\hline $\begin{array}{l}\text { Sorafenib } 400 \mathrm{mg} \text { po qd } \\
\text { Placebo }\end{array}$ & $\begin{array}{l}\text { Surgery or } \\
\text { local ablation }\end{array}$ & III, RC, DB & Target:1,114 & & $\begin{array}{l}\text { NCT00692770 } \\
\text { (STORM trial) }\end{array}$ \\
\hline $\begin{array}{l}\text { Sorafenib } 400 \mathrm{mg} \text { po qd } \\
\text { Placebo }\end{array}$ & Surgery & II, OL & $\begin{array}{l}14 \\
16\end{array}$ & $\begin{array}{l}\text { Not reached } \\
\qquad \begin{array}{l}6 \\
(P=0.008)\end{array}\end{array}$ & {$[70]$} \\
\hline $\begin{array}{l}\text { Sorafenib } 400 \mathrm{mg} \text { po qd } \\
\text { Placebo }\end{array}$ & OLT & II, RC, DB & Target: 356 & & NCT01624285 \\
\hline $\begin{array}{l}\text { PI-88 } 160 \text { mg sc qd } \\
\text { Placebo }\end{array}$ & Surgery & III, RC, DB & Target: 500 & & NCT01402908 \\
\hline $\begin{array}{l}\text { PI-88 } 160 \text { and } 250 \mathrm{mg} \\
\text { sc qd for nine } 4 \text {-week } \\
\text { treatment cycles } \\
\text { No adjuvant treatment }\end{array}$ & Surgery & II, RC, OL & 168 & $\begin{array}{c}10.8^{*} \\
(160 \mathrm{mg} / \text { day }) \\
5.1^{*} \\
(\mathrm{P}=0.13)\end{array}$ & {$[71]$} \\
\hline
\end{tabular}

OLT $=$ orthotopic liver transplant; sc $=$ subcutaneous injection. $*$ Time-to-recurrence at the 36 th percentile.

uating the efficacy and/or safety of radiotherapy in combination with sorafenib in patients with early HCC are actively recruiting patients.

\section{Other Anti-angiogenic Agents and Everolimus}

Several phase II trials explored the efficacy of combining TACE and anti-angiogenic agents, such as sunitinib [65], bevacizumab [66, 67] and orantinib (TSU-68) [68]. Most of these trials demonstrated promisingly long TTP. Further phase III, randomized, controlled trials exploring the combinations of TACE and sunitinib (TURNE trial), orantinib (ORIENTAL trial) and brivanib (BRISK-TA trial) are ongoing. In addition, the efficacy of DEB-TACE with everolimus is currently being explored in two phase II, randomized, controlled trials.

\section{Clinical Trials of Adjuvant Molecular Targeted Therapy Following Curative Treatment}

The potential of molecular targeted agents as adjuvant therapy after curative surgery, local ablation or liver transplantation is under active investigation; most studies are still ongoing. In a phase II trial with a limited number of patients (30 patients in total), sorafenib following curative surgery resulted in a lower tumor recurrence rate (33.3\% vs. $73.6 \%$ ), compared to surgery alone [70]. A large-scale, phase III, randomized, placebo-controlled trial (STORM trial) evaluating the efficacy of sorafenib after curative surgery or local ablation has completed accrual.

PI-88, a heparanase inhibitor, has been testing as adjuvant therapy for HCC after curative resection. A phase II study suggested that PI-88 at $160 \mathrm{mg} /$ day is potentially effective as adjuvant therapy in postoperative HCC patients [71]. A phase III, randomized, placebo-controlled trial exploring the value of PI-88 in the adjuvant setting is ongoing. Data from clinical trials of adjuvant molecular targeted therapy following curative treatment are shown in table 3 $[70,71]$. 


\section{Conclusion}

We have provided a comprehensive overview of recently reported and ongoing clinical trials in HCC. The trials are categorized in a way that helps investigators from diverse disciplines to grasp easily a full picture of research in this field. We intend to provide updated versions of this article on a regular basis.

\section{References}

1 Llovet JM, Ricci S, Mazzaferro V, et al: Sorafenib in advanced hepatocellular carcinoma. N Engl J Med 2008;359:378-390.

2 Cheng AL, Kang YK, Chen Z, et al: Efficacy and safety of sorafenib in patients in the Asia-Pacific region with advanced hepatocellular carcinoma: a phase III randomised, double-blind, placebo-controlled trial. Lancet Oncol 2009;10:25-34.

3 Cheng AL, Kang Y, Lin D, et al: Phase III trial of sunitinib (Su) versus sorafenib (So) in advanced hepatocellular carcinoma (HCC). J Clin Oncol 2011;29 (Suppl: abstr 4000).

4 Barone C, Basso M, Biolato M, et al: A phase II study of sunitinib in advanced hepatocellular carcinoma. Dig Liver Dis 2013 Feb 11.

5 Johnson P, Qin S, Park JW, et al: Brivanib (BRI) versus sorafenib (SOR) as first-line therapy in patients with unresectable, advanced hepatocellular carcinoma (HCC): results from the phase 3 BRISK-FL study. 63rd Annual Meeting of the American Association for the Study of Liver Disease 2012; abstr LB-6.

-6 Llovet JM, Decaens T, Raoul JL, et al: Brivanib versus placebo in patients with advanced hepatocellular carcinoma (HCC) who failed or were intolerant to sorafenib: results from the phase 3 BRISK-PS study. 47th International Liver Congress (EASL) 2012;abstr 1398.

7 Park JW, Finn RS, Kim JS, et al: Phase II, open-label study of brivanib as first-line therapy in patients with advanced hepatocellular carcinoma. Clin Cancer Res 2011;17:1973-1983.

-8 Finn RS, Kang YK, Mulcahy M, et al: Phase II, open-label study of brivanib as second-line therapy in patients with advanced hepatocellular carcinoma. Clin Cancer Res 2012;18:2090-2098.

9 Cainap C, Qin S, Huang WT, et al: Phase III trial of linifanib versus sorafenib in patients with advanced hepatocellular carcinoma (HCC). J Clin Oncol 2013;30 (Suppl 34: abstr 249).

10 Toh HC, Chen PJ, Carr BI, et al: Phase 2 trial of linifanib (ABT-869) in patients with unresectable or metastatic hepatocellular carcinoma. Cancer 2013;119:380-387.

11 Mitsunaga S, Ikeda M, Ueno H, et al: Phase I/II study of lenvatinib (E7080), a multitargeted tyrosine kinase inhibitor, in patients (pts) with advanced hepatocellular carcinoma (HCC): Phase I results. J Clin Oncol 2012;30 (Suppl 4: abstr 231).

12 Okita K, Kumada H, Ikeda K, et al: Phase I/II study of E7080 (lenvatinib), a multitargeted tyrosine kinase inhibitor, in patients (pts) with advanced hepatocellular carcinoma (HCC): initial assessment of response rate. J Clin Oncol 2012;30 (suppl 4: abstr 320).

13 Boige V, Malka D, Bourredjem A, et al: Efficacy, safety, and biomarkers of single-agent bevacizumab therapy in patients with advanced hepatocellular carcinoma. Oncologist 2012;17:1063-1072.

14 McNamara MG, Horgan AM, Aspinall A, et al: A phase II trial of second-line axitinib following prior antiangiogenic therapy in advanced hepatocellular carcinoma (HCC). J Clin Oncol 2012;30 (Suppl 34: abstr 314).

15 Zhu AX, Ancukiewicz M, Supko JG, et al: Clinical, pharmacodynamic (PD), and pharmacokinetic (PK) evaluation of cediranib in advanced hepatocellular carcinoma (HCC): A phase II study (CTEP 7147). J Clin Oncol 2012;30 (Suppl: abstr 4112).

16 Alberts SR, Fitch TR, Kim GP, et al: Cediranib (AZD2171) in patients with advanced hepatocellular carcinoma: a phase II North Central Cancer Treatment Group Clinical Trial. Am J Clin Oncol 2012;35:329-333.

17 Hsu C, Yang TS, Huo TI, et al: Vandetanib in patients with inoperable hepatocellular carcinoma: a phase II, randomized, double-blind, placebo-controlled study. J Hepatol 2012;56:1097-1103.

18 Yau T, Chen PJ, Chan P, et al: Phase I dose-finding study of pazopanib in hepatocellular carcinoma: evaluation of early efficacy, pharmacokinetics, and pharmacodynamics. Clin Cancer Res 2011;17:6914-6923.

19 Kanai F, Yoshida H, Tateishi R, et al: A phase I/II trial of the oral antiangiogenic agent TSU-68 in patients with advanced hepatocellular carcinoma. Cancer Chemother Pharmacol 2011;67:315-324.

20 Yen CJ, Shen YC, Shiah HS, et al: Early data from a phase I study of nintedanib (BIBF 1120) in Asian patients with advanced hepatocellular carcinoma. ESMO Congress 2012;abstr 744P.

21 Palmer D, Loemb AB, Studeny M, Hocke J, Meyer T: Phase I study of nintedanib (BIBF1120) in European patients with advanced hepatocellular carcinoma. ESMO congress 2012; abstr 2831.

22 Zhu AX, Rosmorduc 0, Evans J, et al: SEARCH: a phase III, randomized, double-blind, placebo-controlled trial of sorafenib plus erlotinib in patients with hepatocellular carcinoma (HCC). ESMO Congress 2012; abstr 917.

23 Govindarajan R, Siegel E, Makhoul I, Williamson S: Bevacizumab and erlotinib in previously untreated inoperable and metastatic hepatocellular carcinoma. Am J Clin Oncol 2013;36:254-257. 
24 Philip PA, Mahoney MR, Holen KD, et al: Phase 2 study of bevacizumab plus erlotinib in patients with advanced hepatocellular cancer. Cancer 2012;118:2424-2430.

-25 Yau T, Wong H, Chan P, et al: Phase II study of bevacizumab and erlotinib in the treatment of advanced hepatocellular carcinoma patients with sorafenib-refractory disease. Invest New Drugs 2012;30:2384-2390.

26 Finn RS, Ponn RTP, Yau T, et al: Phase I study of everolimus in combination with sorafenib in patients with advanced hepatocellular carcinoma (HCC). J Clin Oncol 2011;29 (Suppl: abstr 4074).

27 Treiber G, Thomas W, Schneider G, et al: Treatment of advanced or metastatic hepatocellular cancer (HCC): Final clinical results of a single-arm phase II study of bevacizumab and everolimus. J Clin Oncol 2012;30 (Suppl: abstr 4017).

28 Zhu AX, Abrams TA, Miksad R, et al: Phase 1/2 study of everolimus in advanced hepatocellular carcinoma. Cancer 2011;117:5094-5102.

29 Shiah HS, Chen CY, Dai CY, et al: Randomised clinical trial: comparison of two everolimus dosing schedules in patients with advanced hepatocellular carcinoma. Aliment Pharmacol Ther 2013;37:62-73.

30 Kelley RK, Nimeiri HS, Munster PN, et al: Phase I trial of temsirolimus (TEM) plus sorafenib (SOR) in advanced hepatocellular carcinoma (HCC) with pharmacokinetic (PK) and biomarker correlates. J Clin Oncol 2012;30 (Suppl: abstr 4102).

31 Knox JJ, Qin R, Strosberg JR, et al: A phase II trial of temsirolimus (TEM) and bevacizumab (BEV) in patients with advanced hepatocellular carcinoma (HCC). J Clin Oncol 2012;30 (Suppl: abstr 4099).

32 Chelis L, Deftereos S, Xenidis N, et al: Bevacizumab plus temsirolimus as second-line treatment for advanced hepatocellular carcinoma (HCC). J Clin Oncol 2012;30 (Suppl: abstr e14567).

33 Decaens T, Luciani A, Itti E, et al: Phase II study of sirolimus in treatment-naive patients with advanced hepatocellular carcinoma. Dig Liver Dis 2012;44:610-616.

-34 Choo S, Chowbay B, Ng Q, et al: A phase I dose-finding and pharmacodynamic study of rapamycin in combination with bevacizumab in patients with unresectable hepatocellular carcinoma. J Clin Oncol 2010;28 (Suppl: abstr 4097).

35 Santoro A, Rimassa L, Borbath I, et al: Tivantinib for second-line treatment of advanced hepatocellular carcinoma: a randomised, placebo-controlled phase 2 study. Lancet Oncol 2013;14:55-63.

-36 Santoro A, Simonelli M, Rodriguez-Lope C, et al: A Phase-1b study of tivantinib (ARQ 197) in adult patients with hepatocellular carcinoma and cirrhosis. Br J Cancer 2013;108:21-24.

37 Cohn AL, Kelley RK, Yang TS, et al: Activity of cabozantinib (XL184) in hepatocellular carcinoma patients (pts): results from a phase II randomized discontinuation trial (RDT). J Clin Oncol 2012;30 (Suppl 4: abstr 261).

38 O'Neil BH, Bendell JC, Modiano MR, et al: Phase I/II study of E7050 (golvatinib) in combination with sorafenib in patients (pts) with advanced hepatocellular carcinoma (HCC): Phase I results. J Clin Oncol 2013;31 (Suppl: abstr 294).

39 Yau TC, Sukeepaisamjaroen W, Chao Y, et al: A phase I/II study of foretinib, an oral multikinase inhibitor targeting MET, RON, AXL, TIE-2, and VEGFR in advanced hepatocellular carcinoma (HCC). J Clin Oncol 2012;30 (Suppl: abstr 4108).

-40 O’Neil BH, Goff LW, Kauh JS, et al: Phase II study of the mitogen-activated protein kinase 1/2 inhibitor selumetinib in patients with advanced hepatocellular carcinoma. J Clin Oncol 2011;29:2350-2356.

41 Choo SP, Ng QS, Chen WJJ, et al: A phase I/II study of AZD6244 in combination with sorafenib in advanced hepatocellular carcinoma. J Clin Oncol, 2012;30 (Suppl: abstr 4100).

42 Lim HY, Yen CJ, Tak WK, et al: A phase II trial of MEK inhibitor BAY 86-9766 in combination with sorafenib as first-line systemic treatment for patients with unresectable hepatocellular carcinoma (HCC). J Clin Oncol 2012;30 (Suppl 4: abstr 4103).

43 Abou-Alfa GK, Gansukh B, Chou JF, et al: Phase II study of cixutumumab (IMC-A12, NSC742460; C) in hepatocellular carcinoma (HCC). J Clin Oncol 2011;29 (Suppl 4: abstr 4043).

44 Faivre S, Zappa M, Vilgrain V, et al: Changes in tumor density in patients with advanced hepatocellular carcinoma treated with sunitinib. Clin Cancer Res 2011;17:4504-4512.

45 Bitzer M, Giannini EG, Horger M, et al: Efficacy, tolerability and pharmacokinetics of the oral histone deacetylase inhibitor resminostat in patients with advanced hepatocellular carcinoma: clinical data from the phase II SHELTER study. International Liver Cancer Association (ILCA) meeting 2012; abstr.

46 Yeo W, Chung HC, Chan SL, et al: Epigenetic therapy using belinostat for patients with unresectable hepatocellular carcinoma: a multicenter phase I/II study with biomarker and pharmacokinetic analysis of tumors from patients in the Mayo Phase II Consortium and the Cancer Therapeutics Research Group. J Clin Oncol 2012;30:3361-3367.

47 Sun W, Nelson D, Alberts SR, et al: Phase Ib study of mapatumumab in combination with sorafenib in patients with advanced hepatocellular carcinoma (HCC) and chronic viral hepatitis. J Clin Oncol 2011;29 (Suppl 4: abstr 261).

48 Cheng AL, Kang YK, Ryoo BY, et al: Evaluating the safety and tolerability of tigatuzumab (CS-1008) in combination with sorafenib in patients with advanced hepatocellular carcinoma: data from a phase IB doseescalation portion of a phase 2 randomized study. International Liver Cancer Association (ILCA) meeting 2012;abstr P-196.

49 Lee AS, Zee BCY, Cheung FY, et al: Randomized phase II study of the x-linked inhibitor of apoptosis (XIAP) antisense AEG35156 in combination with sorafenib in patients with advanced hepatocellular carcinoma (HCC). J Clin Oncol 2012;30 (Suppl: abstr 4105). 
50 MeleroI, Sangro B, Riezu-Boj RI, et al: Antiviral and antitumoral effects of the anti-CTLA4 agent tremelimumab in patients with hepatocellular carcinoma (HCC) and chronic hepatitis C virus (HCV) infection: results from a phase II clinical trial. Cancer Res 2012;72(Suppl 1: abstr 4387).

51 Stemmer SM, Benjaminov 0, Medalia G, et al: CF102 for the treatment of hepatocellular carcinoma: a Phase I/II, open-label, dose-escalation study. Oncologist 2013;18:25-26.

52 Zhu AX, Gold PJ, El-Khoueiry AB, et al: First-in-man phase I study of GC33, a novel recombinant humanized antibody against glypican-3, in patients with advanced hepatocellular carcinoma. Clin Cancer Res 2013;19:920-928.

53 Okusaka T, Ikeda M, Ohkawa S, et al: A phase I study of GC33 in Japanese patients with advanced hepatocellular carcinoma (HCC). J Clin Oncol 2012; 30 (Suppl 34: abstr 234).

54 Safran H, Charpentier K, Kaubisch A, et al: Lenalidomide for second-line treatment of advanced hepatocellular cancer (HCC): A Brown University Oncology Group phase II study. J Clin Oncol 2012; 30 (Suppl: abstr 4098).

55 Kim GP, Mahoney MR, Szydio D, et al: An international, multicenter phase II trial of bortezomib in patients with hepatocellular carcinoma. Invest New Drugs 2012;30:387-394.

56 Okusaka T, Ueno H, Ikeda M, Takezako Y, Morizane C: Phase I study of TAC-101, an oral synthetic retinoid, in Japanese patients with advanced hepatocellular carcinoma. Cancer Sci 2012;103:1524-1530.

57 Goyal L, Muzumdar MD, Zhu AX: Targeting the HGF/c-MET pathway in hepatocellular carcinoma. Clin Cancer Res 2013;19:2310-2318.

58 Kudo M, Imanaka K, Chida N, et al: Phase III study of sorafenib after transarterial chemoembolisation in Japanese and Korean patients with unresectable hepatocellular carcinoma. Eur J Cancer 2011;47:21172127.

59 Sansonno D, Lauletta G, Russi S, Conteduca V, Sansonno L, Dammacco F: Transarterial chemoembolization plus sorafenib: a sequential therapeutic scheme for HCV-related intermediate-stage hepatocellular carcinoma: a randomized clinical trial. Oncologist 2012;17:359-366.

60 Lencioni R, Llovet JM, Han G, et al: Sorafenib or placebo in combination with transarterial chemoembolization (TACE) with doxorubicin-eluting beads (DEBDOX) for intermediate-stage hepatocellular carcinoma (HCC): phase II, randomized, double-blind SPACE trial. J Clin Oncol 2012;30 (suppl 4: abstr LBA154).

61 Chung YH, Han G, Yoon JH, et al: Interim analysis of START: Study in Asia of the combination of TACE (transcatheter arterial chemoembolization) with sorafenib in patients with hepatocellular carcinoma trial. Int J Cancer 2013;132:2448-2458.

62 Park JW, Koh YH, Kim HB, et al: Phase II study of concurrent transarterial chemoembolization and sorafenib in patients with unresectable hepatocellular carcinoma. J Hepatol 2012;56:1336-1342.

63 Pawlik TM, Reyes DK, Cosgrove D, Kamel IR, Bhagat N, Geschwind JF: Phase II trial of sorafenib combined with concurrent transarterial chemoembolization with drug-eluting beads for hepatocellular carcinoma. J Clin Oncol 2011;29:3960-3967.

64 Sieghart W, Pinter M, Reisegger M, et al: Conventional transarterial chemoembolisation in combination with sorafenib for patients with hepatocellular carcinoma: a pilot study. Eur Radiol 2012;22:1214-1223.

65 Lyer RV, Tomaszewski G, Wu YV, et al: Advanced hepatocellular carcinoma (HCC) treated with sunitinib (Su) and transarterial chemoembolization (TACE): Phase II trial final report. J Clin Oncol 2012;30 (suppl 4: abstr 275).

66 Britten CD, Gomes AS, Wainberg ZA, et al: Transarterial chemoembolization plus or minus intravenous bevacizumab in the treatment of hepatocellular cancer: a pilot study. BMC Cancer 2012;12:16.

67 Buijs M, Reyes DK, Pawlik TM, et al: Phase 2 trial of concurrent bevacizumab and transhepatic arterial chemoembolization in patients with unresectable hepatocellular carcinoma. Cancer 2013;119:10421049.

68 Arai Y, Inaba Y, Yamamoto T, et al: A randomized phase II study of TSU-68 in patients (pts) with hepatocellular carcinoma (HCC) treated by transarterial chemoembolization (TACE). J Clin Oncol 2010;28 (Suppl 15: abstr 4030).

69 Hsu C, Liang PC, Morita S, Hu FC, Cheng AL: Perspectives on the design of clinical trials combining transarterial chemoembolization and molecular targeted therapy. Liver Cancer 2012;1:168-176.

70 Lee KT, Wang SR: The impact of sorafenib on early recurrence of HCC after hepatic surgery. International Liver Cancer Association (ILCA) 2012; 82:abstr P-197.

-71 Liu CJ, Lee PH, Lin DY, et al: Heparanase inhibitor PI-88 as adjuvant therapy for hepatocellular carcinoma after curative resection: a randomized phase II trial for safety and optimal dosage. J Hepatol 2009;50:958-968. 